\title{
Trabalhonecessário
}

Issn: 1808 - 799X

ano 13 , número $21-2015$

\section{MERCOSUL EDUCACIONAL: CONVERGÊNCIA DA POLÍTICA DE EDUCAÇÃO SUPERIOR BRASILEIRA E POLÍTICA DE INTEGRAÇÃO REGIONAL}

Zuleide S. Silveira ${ }^{1}$

\section{Resumo}

Este trabalho busca apreender as modificações na educação superior brasileira por duas mediações: Estado brasileiro e Setor Educacional do Mercado Comum Sul (SEM). Evidencia os esforços de gestão supranacional dos assuntos educacionais e procura compreender a relação entre a grande política, formulada em nível supranacional no SEM e a pequena política, levada adiante no aparelho de Estado brasileiro, em torno da formulação das políticas públicas de educação superior. Desvela os mecanismos institucionais de integração e regionalização da educação superior. A pesquisa baseia-se na análise documental de atas de reuniões, protocolos, planos de ação, tratados e acordos firmados no âmbito do SEM e pelo conjunto de indicações e de legislação formuladas nos mandatos de governos brasileiros, no período 1995-2014.

Palavras-chave: Setor Educacional do Mercosul; Integração Regional; Políticas de Educação Superior

\section{Abstract}

\footnotetext{
${ }^{1}$ Professora da Faculdade de Educação da Universidade Federal Fluminense -
} zuleidesilveira@terra.com.br 


\section{Trabalhonecessário}

Issn: 1808 - 799X

ano 13 , número $21-2015$

This work seeks to seize the recent modifications in Brazilian higher education through two mediations: Brazilian State and Educational Sector of Common Market of South (SEM). It highlights the efforts of supranational management educational affairs and seeks to understand the relationship between the major policy, formulated in supranational level in SEM, and the small politics, led the Brazilian State, in the formulation of public policies about higher education. It unveils the institutional mechanisms of integration and regionalization of higher education. The documentary research analyses minutes of meetings, action plans, protocols, treaties and agreements signed within the framework of SEM and the set of nominations and legislation formulated in terms of Brazilians governments, in the period 1995-2014.

Keywords: Educational Sector of Mercosur; Regional Integration; Higher Education Policies

\section{Introdução}

As três dimensões fundamentais do capital - produção, consumo e circulação/distribuição/realização - tendem a se fortalecer e a se ampliar por meio da internacionalização da economia/tecnologia, operando nas contradições entre imperialismo e dependência, até mesmo em condições extremamente severas de crise estrutural (Mészáros, 2006, p. 796-7). Esta dinâmica capitalista requer estabilidade e previsibilidade institucional, econômica e societária, o que tem implicações na formulação e métodos da ação governamental no âmbito do sistema político-administrativo nacional (Dreifuss, 1997, 2004; Mészáros, 2003; Gramsci,1976; 2007). 


\section{Trabalhonecessário}

Issn: 1808 - 799X

ano 13, número $21-2015$

O projeto estadunidense de reconstrução e regulação do capitalismo internacional, no Pós Segunda Grande Guerra, bem evidencia a lógica tendencial daquela dinâmica em sua fase imperialista: acentuar as estratégias geopolíticas, diplomáticas e militares usadas por um Estado ou bloco de Estados, em meio à luta para afirmar seus interesses e atingir suas metas rumo ao mundo globalizado. Promovem-se as conferências de Bretton Woods e cria-se a Organização do Atlântico Norte (Otan) ${ }^{2}$, precursores do Plano Marshall para a reconstrução da Europa, que veio a ser executado pela Organização para a Cooperação e Desenvolvimento Econômico (Ocde). Constroem-se uma complexa rede de instituições, agrupadas em três setores, de modo a obter a estabilidade e previsibilidade institucional apontada por Dreifuss (op.cit.).

O primeiro setor, formado pelo Fundo Monetário Internacional, Banco Internacional para Reconstrução e o Desenvolvimento (Bird) e Acordo Geral sobre Tarifas e Comércio (Gatt), ficou responsável pela supervisão do comércio e do equilíbrio de balanços de pagamentos dos países membros; o segundo constituiuse da rede global de bases militares legitimadas por vários pactos regionais de segurança coletiva ou de defesa bilateral; e, por último, a Organização das Nações Unidas (ONU), com o Conselho de Segurança, responsável pela administração política de conflitos interestatais e a Organizações da Nações Unidas para a Educação, Ciência e Cultura (Unesco), organismo consultor técnico para assuntos de educação, ciência e cultura.

Trata-se de uma garantia do pleno desenvolvimento capitalista que se dá por mediação do "grande Estado burguês supranacional" (Gramsci, 1976, p. $189)^{3}$, cujo poder privado reúne ministros e secretários de Estado, empresários, engenheiros, executivos, analistas e cientistas. Intelectuais que atuam em

\footnotetext{
2 Do inglês North Atlantic Treaty Organization (Nato).

${ }^{3}$ Talvez Gramsci (1976, p.187-189; 2007, p.24; 80; 151-153 tenha sido o primeiro teórico-marxista a analisar a organização de Estado em blocos que, à época, se configurava na Liga da Nações, modificando as relações de organização político-econômicas no interior dos Estados-Nações, a partir de acordos regionais, notadamente assinados em nível supranacional. .
}

TrabalhoNecessário - www.uff.br/trabalhonecessario; Ano 13, Nº 21/2015. 


\section{Trabalhonecessário}

Issn: 1808 - 799X

ano 13, número $21-2015$

espaços decisórios que relativizam a soberania do Estado-Nação no que diz respeito às trocas internacionais, às barreiras alfandegárias, à livre concorrência, à concentração de capital, bem como à regionalização e integração da educação.

O Mercosul e a UE representam uma das formas institucionais mais avançadas neste domínio, assumindo progressivamente um papel, cada vez mais, ativo na área das políticas sociais, particularmente no domínio da educação (Antunes, 2005). Temas como educação para o desenvolvimento econômico; produção e transferência de ciência e tecnologia; cultura, diversidade cultural e integração regional, entre outros, passam a ser tratados à revelia do público, assumindo o caráter de gestão supranacional no plano da grande política, com implicações na formulação de políticas e na ação governamental no âmbito da pequena política, em nível nacional ${ }^{4}$.

Contudo, o estado burguês supranacional só se sustenta pelos EstadosNações que reúnam condições de inserir-se e enfrentar a concorrência no mercado mundial, particularmente nesta fase de crise estrutural do capital, iniciada nos anos 1970, na qual sua administração vem mediada pelas políticas neoliberais.

Isto quer dizer que, a criação de organismos como a ONU, a Otan, a Unesco, a Ocde, o Banco Mundial, o FMI, a OMC, bem como a integração de

\footnotetext{
${ }^{4}$ Em Gramsci, os conceitos de pequena política e grande/alta política guardam coerência com os "princípios de metodologia histórica" Princípios metodológicos que revelam dois outros conceitos: estrutura e conjuntura. Para Gramsci, "no estudo de uma estrutura, devem-se distinguir os movimentos orgânicos (relativamente permanentes) dos movimentos que podem ser chamados de conjuntura (e que se apresentam como ocasionais, imediatos, quase acidentais). Também os fenômenos de conjuntura dependem, certamente, de movimentos orgânicos, mas seu significado não tem um amplo alcance histórico. Eles dão lugar a uma crítica política miúda, do dia-a-dia, que envolve os pequenos grupos dirigentes e as personalidades imediatamente responsáveis pelo poder. Os fenômenos orgânicos [estruturais] dão lugar à crítica histórico-social, que envolve grandes agrupamentos, para além das pessoas imediatamente responsáveis e do pessoal dirigente" (Gramsci, 2007, p. 36-37; 1981, p. 343-344). Daí, a pequena política ser entendida não como algo menor, mas aquela que trata de questões parciais, conjunturais e cotidianas das disputas entre frações políticas na arena do Estado. E, a grande política, denominada também de alta política, dizer respeito à fundação ou à reorganização do Estado supranacional em torno da luta, seja pela destruição, seja pela defesa ou pela conservação da estrutura econômico-social organizada em nível internacional (Gramsci, 2007, p. 21-22).
}

TrabalhoNecessário - www.uff.br/trabalhonecessario; Ano 13, No 21/2015. 


\section{Trabalhonecessário}

Issn: 1808 - 799X

ano 13, número $21-2015$

países em blocos político-econômicos, a exemplo do Mercosul e da UE, não engendram o enfraquecimento do Estado ou o torna mínimo. Ao contrário. A tarefa política do Estado encontra-se, hoje mais do que nunca, na criação de medidas necessárias à reprodução social. $\mathrm{O}$ que implica transformá-lo em gerenciador do fundo público, isto é, agente de financiamento simultâneo da acumulação do capital e de reprodução da força de trabalho: financiando a acumulação do capital com gastos públicos na produção através de subsídios para agricultura, indústria, comércio, ciência e tecnologia, e financiando a reprodução da força de trabalho por meio de gastos sociais como educação, medicina socializada, previdência social, seguro-desemprego, vale-transporte, vale-alimentação, habitação, salário-família, etc. (Oliveira, 1988, p. 21-22; 2003, p. 39-40).

Longe de comprovar a falência do Estado, a criação de organismos que atuam em escala global, bem como a de blocos político-econômicos regionais atesta o papel decisivo do poder político de Estado no processo de integração econômica, cujas estruturas econômicas e políticas intra-bloco e entre blocos são determinadas e determinantes pelas/das relações imperialismo e dependência ${ }^{5}$.

Os problemas que se levantam acima colocam a questão da relação trabalho e educação como parte da "necessidade sistêmica de o capital subjugar globalmente o trabalho [e a educação] por meio de toda e qualquer agência social" (Mészáros, 2003, p. 13), de modo a solver as contradições inerentes a sua essência: capital, trabalho e educação; produção, controle e consumo; produção e

\footnotetext{
${ }^{5}$ A especificidade da inserção competitiva do capitalismo brasileiro no mercado mundial, em sua nova fase, é elucidativa. Ela ocorre no âmbito da cooperação antagônica (MARINI, 2000; 1977), marcada pela inserção regressiva da economia brasileira nos mercados regional e mundial, mas também pelo posicionamento ambivalente e contraditório que assume entre países periféricos e países de capitalismo central. Trata-se de um movimento, ao mesmo tempo, cooperativo e conflituoso. De um lado, o empresariado brasileiro demonstra sua subordinação consciente à integração imperialista, mantendo a dependência do padrão tecnológico controlado pelo capital central nos processos de desnacionalização e desindustrialização, enquanto valoriza o modelo agroexportador; de outro, mostra sua face autônoma, adotando, de modo agressivo, uma política de exportação de capitais particularmente para países da América Latina e África.
}

TrabalhoNecessário - www.uff.br/trabalhonecessario; Ano 13, No 21/2015. 


\section{Trabalhonecessário}

Issn: 1808 - 799X

ano 13, número $21-2015$

distribuição; competição e monopólio; competição, integração, regionalização e internacionalização.

Neste sentido, o processo de regionalização econômica por mediação do Mercosul, que abre caminho para a integração de outros setores, como o educacional, não pode ser negligenciado. $E$, tampouco, o processo de institucionalização birregional da educação superior (UE e Mercosul). Ambos os blocos visam a educação como fator de integração e peça-chave para a consolidação e projeção de seus Estados Membros e respectivo bloco no mercado mundial, afirmando seu papel precípuo na produção e transmissão do conhecimento científico-tecnológico orientado para o desenvolvimento econômico e a modernização.

Este trabalho busca apreender as modificações na educação superior brasileira por duas mediações: Estado brasileiro e Setor Educacional do Mercado Comum Sul (SEM). O texto está estruturado da seguinte forma: primeiro expõe a gênese da criação do Mercosul e os sucessivos acordos com a UE, de modo a captar a dinâmica político-econômica regional na sua relação com a educação. Em seguida, evidencia os esforços de gestão supranacional dos assuntos educacionais, particularmente da educação superior, sob a ação do marco regulatório do SEM ${ }^{6}$. Desvela os mecanismos institucionais que, por mediação do Estado brasileiro, vêm propiciando a integração e regionalização da educação superior brasileira, particularmente por meio da avaliação e da mobilidade. Por fim, a título de primeiras aproximações, aponta para a institucionalização da educação em âmbito birregional (UE e Mercosul). $O$ tempo da pesquisa remonta à gênese do Mercosul, no início dos anos 1990, estendendo-se até os dias atuais, com base na análise documental de atas de reuniões, protocolos, planos de ação, tratados e acordos firmados no âmbito do SEM e pelo conjunto de indicações e de legislação formuladas nos mandatos de governo de 1995 a 2014, de modo a

${ }^{6}$ O Setor Educacional do Mercosul é denominado também de Mercosul Educacional.

TrabalhoNecessário - www.uff.br/trabalhonecessario; Ano 13, No 21/2015. 


\section{Trabalhonecessário}

Issn: 1808 - 799X

ano 13, número $21-2015$

compreender a ação política dos sujeitos envolvidos na formulação das políticas de educação superior segundo seus tempos e lugares.

\section{Da integração político-econômica à integração da educação}

Na América Latina, o entusiasmo em torno da integração regional, sob a égide do mercado comum, foi deslanchado pela Comissão Econômica para América Latina e Caribe (Cepal) dos anos de 1960/70. Entretanto, será com a criação do Mercosul que se intensificam os processos de integração intrarregional, adotando a perspectiva do regionalismo aberto, segundo o qual zonas de livre-comércio e uniões aduaneiras são vistas como veículos à inserção no mercado mundial (Trein; Cavalcanti, 2007).

Tendo a UE como segundo maior investidor, a seguir aos Estados Unidos da América do Norte (EUA) e muito à frente do Japão, o Mecosul, instituído pelo Tratado de Assunção, de 1991, tem sua gênese em um contexto particular da trajetória dos países que o integram ${ }^{7}$ : a necessidade de superar os efeitos negativos da década perdida. Inseridos na "terceira onda de democratização" (Huntington, 1994), Argentina e Brasil, líderes do bloco econômico, viam na criação do Mercosul uma estratégia de redução da vulnerabilidade das economias da região frente à hegemonia norte-americana.

Com o aprofundamento do processo de integração (neoliberal) regional e a maior necessidade, por parte do capital, de intensificar relações com os países membros da América Latina, o Mercosul incorpora os Estado Associados (op.cit.). Neste movimento, busca-se oferecer, de um lado, resistência às sucessivas negociações multilaterais em torno da Área de Livre Comércio das Américas (Alca) tal como propunham os EUA: incluir na OMC o debate sobre os novos temas (investimentos, compras governamentais, políticas de concorrência) e o

\footnotetext{
${ }^{7} \mathrm{Na}$ origem do MERCOSUL, os Estados Partes eram Argentina, Brasil, Paraguai e Uruguai, mais tarde juntam-se Venezuela (no ano de 2012) e Bolívia (que encontra-se em processo de adesão). O bloco possui o reforço de Estados Associados como Chile, Colômbia, Equador, Guiana e Suriname.
}

TrabalhoNecessário - www.uff.br/trabalhonecessario; Ano 13, No 21/2015. 


\section{Trabalhonecessário}

Issn: 1808 - 799X

ano 13, número $21-2015$

Trip Plus (requisitos de proteção dos direitos de propriedade intelectual, mais rigorosos do que aqueles exigidos pela $\mathrm{OMC}$ ). De outro, estreitar a cooperação com a UE que tem na integração extrarregional a perspectiva de formar uma divisão do trabalho birregional, de modo a favorecer novos fluxos de investimento, de circulação de produtos, serviços, pessoal qualificado e conhecimento, aumentando assim o fator de competitividade frente aos EUA e ao Japão.

Expressão dessa aproximação, no plano mais abrangente, são os sucessivos acordos de associação estratégica, firmados entre chefes de Estado e de Governo na Cúpula União Europeia e América Latina e Caribe (UE-ALC), a exemplo da Declaração de Rio de Janeiro, Brasil (1999); Declaração de Madrid, Espanha (2002); Declaração de Guadalajara, México (2004); Declaração de Viena, Áustria (2006); Declaração de Lima, Peru (2008); Declaração de Madrid, Espanha (2010); Declaração de Santiago, Chile (2013) .

A plataforma de relações comerciais, investimentos e serviços das referidas Declarações vem acolhendo as propostas do setor empresarial, cujos líderes se reúnem em torno do Fórum Empresarial UE-ALC. Organizado nas trincheiras da Cúpula de Chefes de Estado e de Governo (UE-ALC), o fórum empresarial trata de temas como Aproximar os dois mundos através dos Negócios e da Cultura (2006); Inversão para o Bem-estar, o Desenvolvimento Sustentável e a Inclusão (2008); Investimentos para o crescimento econômico, a inclusão social e a sustentabilidade ambiental (2013) ${ }^{9}$.

\footnotetext{
${ }^{8}$ Com a formalização da Cúpula da Comunidade dos Estados Latino-Americanos e Caribenhos (Celac), como contraponto à Organização dos Estados Americanos (OEA) capitaneada pela hegemonia estadunidense, novos contornos geopolíticos vêm sendo construídos. A Celac tem como diretrizes principais, ampliar o diálogo político e realizar projetos de cooperação entre os 33 países da ALC, com o fito de definir a identidade regional calcada nas concepções latinoamericanas e caribenhas comuns sobre integração e desenvolvimento. Contudo e a despeito da presença de chefes de governos marcadamente anti-imperialistas (Cuba, Equador, Bolívia, Uruguai, Venezuela), desde 2013 que a Celac vem aliando-se com a União Europeia no processo de parceria birregional.Cf. Brasil (2012).

9 Do Fórum Empresarial UE-ALC participam, entre outros representantes do empresariado, o presidente de Business Europe, o presidente da Confederação Espanhola de Organizações Empresarial, o Presidente da Confederação de Empresários Latino-Americanos, o presidente
} 


\section{Trabalhonecessário}

Issn: 1808 - 799X

ano 13, número $21-2015$

O Fórum Empresarial UE-ALC reconhece a importância do investimento em ciência, tecnologia e inovação (C,T\&l) para o desenvolvimento econômico, considerando prioritária, para tanto, a criação de um Espaço Comum do Ensino Superior UE-ALC orientado para a mobilidade e a cooperação birregional, por mediação de programas de intercâmbios do conhecimento (estudantil e pesquisadores) e de trabalhadores qualificados.

Mais do que facilitar o intercâmbio do conhecimento e de mobilidade trabalhadores qualificados, busca-se promover um movimento sincrônico de sistemas de educação superior, entre blocos e intrabloco, com o fito de fortalecer um sistema de transferência e validação de créditos interinstitucional e internacional. Prevê-se instituir as condições necessárias para solidificar a interface entre pesquisa e inovação, facilitando a transferência e adaptação de tecnologia às empresas (UE-ALC, Declaração de Madrid, 2010).

Em nível mais abrangente, esta relação entre UE-ALC não se descura do papel crucial do Mercosul na sua relação com a UE. O projeto político estratégico do Mercosul, compartilhado pelos seus Estados (Partes e Associados), vem se consolidando em torno da União Aduaneira, da integração das cadeias produtivas e dos serviços ${ }^{10}$. Além deste aspecto, os Estados membros do Mercosul estão entre os beneficiários mais ativos da relação UE e Mercosul em que destacam-se - Acordo Quadro Interregional de Cooperação (1995); a Declaração Comum (2007); Documento de Estratégia Regional [2007-2013] (2007); a Declaração Comum (2008); o Comunicado Conjunto da Reunião Ministerial Mercosul-Troika UE (2009); e o Programa Regional para 2007-2013.

Com este arcabouço normativo birregional, busca-se estreitar laços, já manifestos no Acordo Quadro de 1995, em matéria de normas agro-alimentares e

executivo da Organização Internacional de Empregadores. A Confederação Nacional da Indústria (CNI) possui relação estreita com o Fórum sem, no entanto, dele participar diretamente devido ao seu interesse de aproximar-se também dos EUA, Canadá, México e Japão. Sua presença é marcante no(s) Encontro(s) Empresarial(is) UE-Brasil promovidos em âmbito nacional.

10 Para maiores detalhes, ver Novoa (2009). 


\section{Trabalhonecessário}

Issn: 1808 - 799X

ano 13 , número $21-2015$

industriais (op,cit. art. 6으), cooperação aduaneira (op,cit., art. 7으), cooperação de propriedade intelectual (op.cit., art. 9ํ) e cooperação empresarial op.cit., art. 11으), entre outras, com a finalidade de aumentar os fluxos de trocas comerciais, os investimentos, os projetos de cooperação industrial e a transferência de tecnologias; apoiar a modernização e diversificação industrial; favorecer a inovação industrial, por mediação de conferências, seminários técnicos, missões exploratórias, participação em feiras gerais e setoriais e em encontros empresariais; além do incentivo à iniciativa privada por meio do investimento colaborativo em C,T\&I (MERCOSUL-UE/ACORDO, 1995).

Daí a instrumentalização da educação seja pelo Estado seja pelos organismos supranacionais. Se o processo de internacionalização da economia, em níveis mundial e regional, inclui o comércio e fluxos internacionais de capitais, de trabalhadores, bem como a entrada e saída de tecnologias incorporada aos equipamentos, toda esta dinâmica engendra formas de trabalho e de produção de conhecimento em redes, do que estudantes, docentes-pesquisadores, pessoal qualificado em pesquisa e desenvolvimento (P\&D) fazem parte. Nesta dinâmica, a educação superior é orientada a responder de modo imediato e mediato às dinâmicas do processo de internacionalização/regionalização da economia/tecnologia, por mediação das políticas de C,T\&I, assumindo, assim, caráter internacionalizado/regionalizado.

Não é por acaso que os Programas-Quadros de investigação, seja em parceria com a UE, seja na estrutura institucional do Mercosul, têm como estratégia o processo de internacionalização produtiva. A cooperação científica europeia com países do Mercosul assenta em projetos de pesquisa competitivos, segundo os sucessivos programas-quadro de investigação (PQ5 - 1998-2002; PQ6 - 2002-2006), tendo o Brasil e a Argentina participação significativa nesse processo, apresentando mais de cem projetos no período. (MercosulUE/Documento Estratégia Regional, 2007, p.24). 


\section{Trabalhonecessário}

Issn: 1808 - 799X

ano 13, número $21-2015$

Este conjunto de relações sócio-institucionais pode ser encarado como uma das características da contraditória riqueza capitalista revelada ao analisarmos seu conteúdo e forma social histórica.

\section{O processo de integração da educação superior brasileira}

Na seção anterior, vimos que a dinâmica de integração político-econômica requer o desenvolvimento de políticas educacionais coerentes com as políticas de C,T\&l na perspectiva de agregar valor à produção regional (Mercosul/CMC/Programa Quadro 2008-12, 2008, p. 6-7).

Foi com a finalidade de construir instrumentos e canais que viessem favorecer a circulação de capital, tecnologia, pessoal qualificado, informações e dados tanto em âmbito intrarregional (Mercosul) quanto birregional (UE e Mercosul) que, desde a criação do Mercosul, em 1991,

los gobiernos que integran el pacto regional convinieron en atender una serie de temas colaterales al intercambio comercial, en particular los relativos al área de trabajo, justicia y educación. En efecto, el tema educativo fue puesto en relieve como un aspecto de importancia por los países miembros para llevar adelante el proceso de constitución comunitaria. En las reuniones previas al Tratado de Asunción y en la propia reunión fundacional, se fue definiendo una agenda de problemas y objetivos comunes que deberían atenderse por medio de la constitución de un proyecto específico para tal función: El Sector Educativo del MERCOSUR (...) Al mismo momento que el SEM intenta afianzarse como un instrumento para la construcción de nuevos espacios para el desarrollo económico, político y cultural fortalecedor de la identidad regional en un mundo globalizado, un importante debate en torno a la internacionalización de la educación superior viene llevándose a cabo desde la década de los 90's en el seno de organismos internacionales UNESCO/OMC (Fulquet, 2006, p. 5). 


\section{Trabalhonecessário}

Issn: 1808 - 799X

ano 13, número $21-2015$

Com efeito, do ato de criação do SEM, em 1991, no qual se firmou o Protocolo de Intenções ${ }^{11}$, passando pelos Planos de Ação executados ao longo as últimas duas décadas (1992/1994-1998²;1998-2000; 2001-2005; 2006-2010; 2011-2015), ao Termo de Cooperação Técnica Mercosul-UE para o período 20072013/Programa de Bases para o Mercado Comum ${ }^{13}$, vêm sendo criados mecanismos facilitadores do reconhecimento e da padronização/equiparação de estudos, da livre circulação de estudantes, do intercâmbio de docentes universitários e da formação de pessoal qualificado, graduados e pós-graduados, com a finalidade de criar o Espaço Comum Regional de Educação Superior (Mercosul/SEM, 2000) ${ }^{14}$.

\footnotetext{
${ }^{11}$ Assinado em 13/12/1991, em Brasília, pelos Ministros da Educação da Argentina, do Brasil, do Paraguai e do Uruguai. A parte brasileira esteve representada por Antonio Teixeira de Souza Júnior, Ministro Interino da Educação no governo Collor de Mello. Disponível em http://www.sic.inep.gov.br/pt/documentos/cat view/98-documentos-e-referencias/45-acordos-acuerdos--agreements/96-acordos-de-ministros--acuerdos-de-ministros--ministers-agreements. 12 Delineado para ser implementado entre 1992 e 1994, o 1ํ Plano foi prorrogado até junho de 1998, devido às modificações introduzidas na estrutura institucional do MERCOSUL, pelo Tratado de Ouro Preto.

${ }^{13}$ O referido termo insere-se no Documento de Estratégia Regional (2007-2013) (op.cit.).

${ }^{14}$ Nos Planos subsequentes a referência ao espaço comum de educação superior é substituída por Espaço Educacional Comum, evidenciando a coordenação de políticas que articulam todos os níveis da educação com o processo de integração econômica do MERCOSUL. Cf. Mercosul/SEM (2011).
} 


\section{Trabalhonecessário}

Issn: 1808 - 799X

ano 13, número $21-2015$

Organograma do Setor Educacional do Mercosul ${ }^{15}$

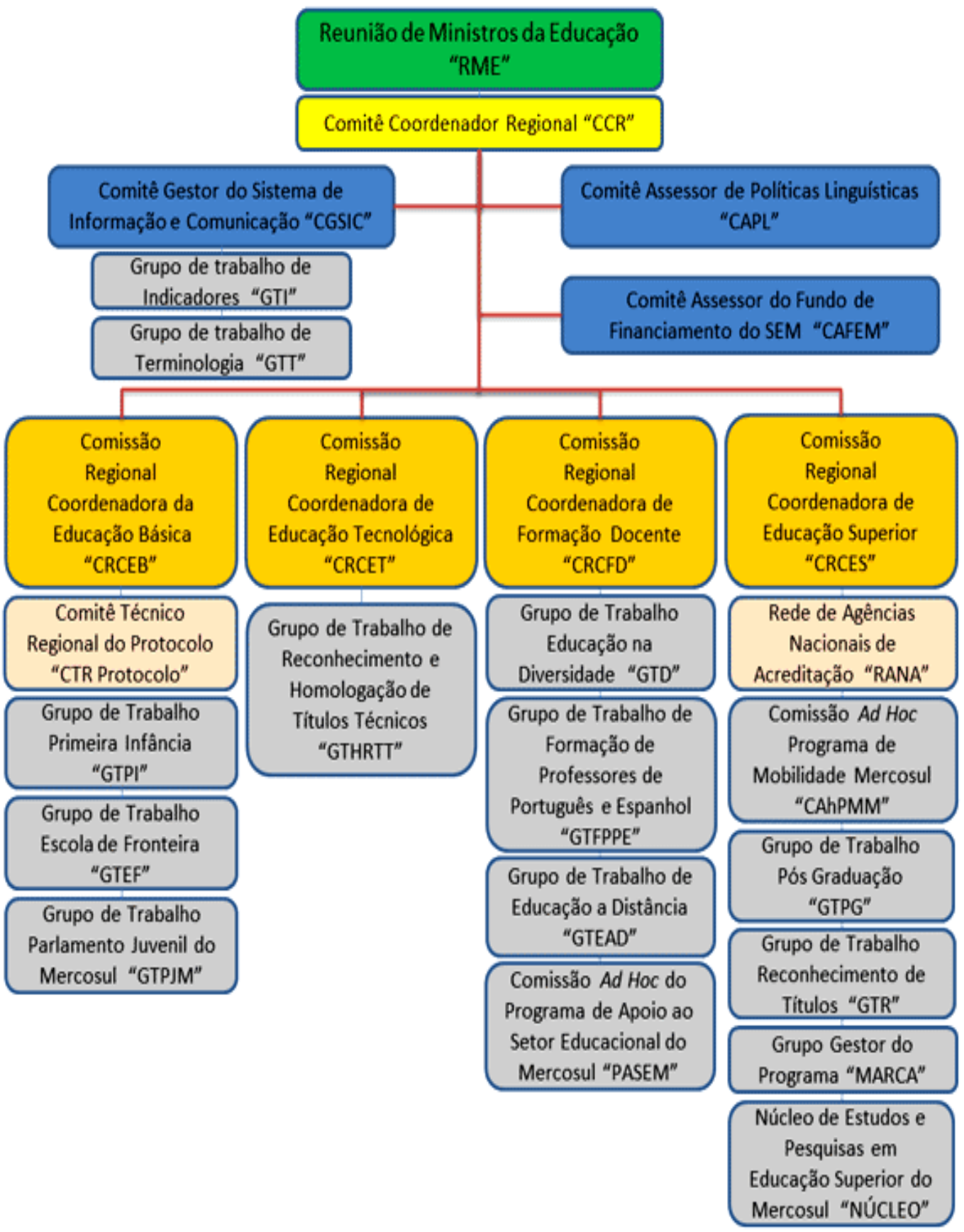

15 O SEM mantém vínculos com: Celac, Cepal, OEA, OEI, Unesco, UE, Instituto de Avaliação e Acompanhamento da Metas Educacionais 20121; Sistema de Informações de Tendências Educacionais na América Latina e União de Nações Sul-Americanas.

TrabalhoNecessário - www.uff.br/trabalhonecessario; Ano 13, Nº 21/2015. 


\section{Trabalhonecessário}

Issn: 1808 - 799X

ano 13, número $21-2015$

Fonte: SEM: Instâncias do Setor Educacional do Mercosul (2012).

Entrementes, foram efetuadas alterações significativas na estruturainstitucional do bloco, particularmente na organização do SEM, com o objetivo de conceder maior eficiência e legitimidade aos planos de ação ${ }^{16}$. $O$ organograma, acima, mostra a complexa estrutura do Mercosul Educacional, consoante o Plano de Ação do Setor Educacional do Mercosul 2011-2015.

Homens de seu tempo, os intelectuais que atuam no SEM, ao elaborar os Planos de Ação, afinam-se às orientações de ordem metodológica e financeira do BM, da Ocde, da Unesco e da Cepal ${ }^{17}$. Busca-se elevar a produtividade do trabalho, partindo do pressuposto que educação e conhecimento são o eixo da transformação produtiva, equidade social e democratização política. Nesta perspectiva, a educação contribui na formação de uma consciência integradora, de aquisição de novos hábitos, atitudes e competências laborais, bem como aperfeiçoa o capital humano para ingressar na mobilidade, cujo movimento virtuoso é o da circulação de bens, serviços e capitais.

Essa concepção de educação atua no sistema educacional por meio de três vetores: o primeiro, de cima para baixo, vinculando as atividades do SEM aos planos nacionais de educação e aos processos de reforma dos Estados Partes, evidenciando um movimento de gestão supranacional dos assuntos educacionais. O segundo, na direção horizontal, atuando por meio da cooperação entre países intra-bloco ou entre blocos regionais; o terceiro, dirigindo-se à construção do espaço comum de educação, de modo a favorecer o intercâmbio de experiências e práticas laborais, por meio da mobilidade de estudantes, acadêmicos e pesquisadores.

${ }^{16}$ Entre outras modificações na organização do bloco, decorreram a transformação da Secretaria Administrativa em Secretaria Técnica, a criação da Comissão de Representantes Permanentes do Mercosul e de sua Presidência, a instalação do Tribunal Permanente de Revisão e do Tribunal Administrativo Laboral, o Fundo de Convergência Estrutural (Focem), e o estabelecimento do Parlamento do Mercosul.

17 Recentemente, a Cepal afirmou que países periféricos não devem retroceder nas reformas neoliberais, mas sim, retomá-las, implementando um conjunto de políticas econômicas com foco na crise iniciada em 2008. Cf. Cepal, 2010.

TrabalhoNecessário - www.uff.br/trabalhonecessario; Ano 13, No 21/2015. 


\section{Trabalhonecessário}

Issn: 1808 - 799X

ano 13, número $21-2015$

\section{Os mecanismos da integração e regionalização da educação}

Embora o foco deste artigo seja a educação superior, vale registrar que os acordos educacionais, no plano circunscrito ao Mercosul, não se limitam apenas a ela. A integração educacional inclui também a educação básica como bem evidenciam os Protocolo(s) sobre integração educativa e reconhecimento de certificados, título e estudos de nível primário e médio não técnico (Mercosul/Decisão oo 04/94) ${ }^{18}$; de integração educacional, revalidação de diplomas, certificados, títulos e de reconhecimento de estudos de nível médio técnico (Mercosul/Decisão no 07/95); de Integração cultural do Mercosul (Mercosul/Decisão no 11/96), de modo a favorecer o enriquecimento e a difusão de expressões culturais entre os Estados Partes; além do Acordo de admissão de títulos certificados e diplomas para o exercício da docência no ensino do espanhol e do português como línguas estrangeiras nos Estados Partes (Mercosul/Decisão no 09/2005), que encontra-se em pendência ${ }^{19}$.

Nas origens do SEM, visava-se apenas o reconhecimento de títulos para as atividades acadêmicas e não para o exercício da profissão, consoante o Protocolo de Admissão de Títulos y Graus Universitários para o Exercício de Atividades Acadêmicas dos Países do Mercosur (MercosuL/SEM, Dec.no 03, 1997). Entretanto, o Protocolo foi modificado pela Decisão no 04/99, possibilitando docentes brasileiros, argentinos, paraguaios e uruguaios exercerem atividades de ensino e pesquisa em cursos de graduação e pós-graduação, em âmbito regional, reconhecidos pelo SEM.

\footnotetext{
${ }^{18}$ No ano de 2010, foi firmado o Protocolo de Integração Educativa e Reconhecimento de Certificados, Títulos e Estudos de Nível Primário/Fundamental/Básico e Médio/Secundário entre os Estados Partes do MERCOSUL e Estados Associados (Decisão no 21/10), que regulamenta a mobilidade estudantil e cria a comissão para atualizar a tabela de equivalência de estudos, segundo as reformas educacionais dos Estados Partes e Associados. Decisão não vigente. Cf. http://www.mercosur.int/t_ligaenmarco.jsp?contentid=4823\&site=1\&channel=secretaria

19 Todos os documentos citados encontram-se em Tratados, Protocolos y Acordos depositados en Paraguay. Disponíve

em http://www.mercosur.int/t_ligaenmarco.jsp?contentid=4823\&site=1\&channel=secretaria
} 


\section{Trabalhonecessário}

Issn: 1808 - 799X

ano 13, número $21-2015$

Os Estados Partes, por meio de seus organismos competentes, admitirão unicamente para o exercício de atividades de docência e pesquisa nas instituições de ensino superior no Brasil, nas universidades e institutos superiores no Paraguai, nas instituições universitárias na Argentina e no Uruguai, os títulos de graduação e pós-graduação reconhecidos e credenciados nos Estados Partes, segundo procedimentos e critérios a serem estabelecido para a implementação deste acordo (Mercosul/SEM/Dec.04, 1999)20.

Todas essas decisões dizem respeito à pedra angular da construção do Espaço educacional comum: a mobilidade e a avaliação. No nível da educação superior, a livre circulação de pesquisadores, docentes e estudantes é uma das metas que vem sendo perseguida pelo SEM desde o Compromisso de Brasília Metas do Plano Trienal para o Ano 200021. A exemplo do que ocorre na UE, com - Processo de Bolonha, a mobilidade estudantil no Mercosul se sucede por mediação do sistema de transferência de créditos.

Ainda que não tenha sido universalizado entre os cursos de graduação reconhecidos pelos Ministérios de Educação dos Estados Partes e Associados, o aproveitamento de estudos vem ocorrendo através do Programa Marca ${ }^{22}$. Marca oferece aos estudantes a possibilidade de cursar um semestre acadêmico em universidades, cujos cursos de graduação foram acreditados conforme o

\footnotetext{
20 No Brasil, a admissão/revalidação dos títulos de graduação e de pós-graduação stricto sensu obtidos no exterior não é automática, devendo ser solicitada a uma universidade reconhecida pelo MEC que conceda título equivalente. Do mesmo modo, qualquer atividade a ser exercida por estrangeiro, mesmo proveniente de países do Mercosul, sua diplomação ou certificação de curso de graduação ou pós-graduação depende de revalidação na forma estabelecida pelo art. 48 da LDB e pela Resolução CNE/CES no 01/2007.

${ }^{21}$ O Compromisso de Brasília, orientador dos trabalhos do SEM, é composto por três partes: Termos de Referência para a Definição do Plano Trienal do Setor Educacional do MERCOSUL, 1998-2000; Plano Trienal 1998-2000 do Setor Educacional do MERCOSUL; Compromisso de Brasília: Metas do Plano Trienal para o Ano 2000. Assinaram o Documento os então ministros Paulo Renato Souza (Ministro da Educação do Brasil); Rafael Jacobo (Vice-Ministro de Educação do Paraguai); Antonio Guerra (Subsecretário de Educação e Cultura do Uruguai); Manuel García Solá (Vice-Ministro de Educação da Argentina). Pelos Estados associados assinou Tito Hoz de Vila Quiroga (Ministro de Educação, Cultura e Desporto da Bolívia).

22 Programa de Mobilidade Acadêmica Regional para os cursos acreditados pelo Sistema de Acreditação de Cursos de Graduação no Mercosul e Estados Associados.
}

TrabalhoNecessário - www.uff.br/trabalhonecessario; Ano 13, No 21/2015. 


\section{Trabalhonecessário}

Issn: 1808 - 799X

ano 13, número $21-2015$

Sistema Arcu-Sul23. Neste sentido, não se pode afirmar que a mobilidade estudantil não vem ocorrendo e, tampouco, que não existe a transferência e validação de créditos interinstitucional e internacional no âmbito da educação superior realizada no Mercosul. Mais adiante, voltaremos ao tema do Marca. Antes, porém, tratemos do processo de acreditação de cursos e da formação da cultura da avaliação.

Segundo o Ministério da Educação (MEC), acreditação é o resultado do processo de avaliação, por meio do qual é certificada a qualidade acadêmica dos cursos de graduação dos Estados Partes e Associados, segundo critérios de qualidade previamente aprovados no âmbito regional. Os diplomas dos cursos acreditados levam um selo de qualidade do SEM.

Para o MEC há uma diferença entre os processos de acreditação e de credenciamento. Este, realizado em nível nacional, se refere à autorização de funcionamento da instituição de ensino superior brasileira, segundo a sua organização acadêmica: faculdade, centro universitário e universidade. Expirada a validade do credenciamento (três anos para faculdades e centros universitários; cinco anos para universidades) e após se submeter ao Sistema Nacional de Avaliação da Educação Superior (Sinaes) ${ }^{24}$, a instituição de ensino solicita o seu recredenciamento, do que o reconhecimento e renovação de cursos fazem parte.

Ainda segundo o MEC, o processo de acreditação do SEM é de responsabilidade das agências nacionais de acreditação que, designadas pelos Ministros de Educação de cada Estado Parte ou Associado, atuam em nível nacional. Deste modo, uma agência nacional de acreditação acaba por se confundir com a comissão nacional de avaliação. No Brasil, de acordo com a Portaria MEC no 1734/2011, a Agência Nacional de Acreditação (ANA) é constituída pela Secretaria de Regulação e Supervisão da Educação Superior

\footnotetext{
${ }^{23}$ Sistema de Acreditação de Cursos de Graduação no Mercosul e Estados Associados.

24 Vinculado ao Instituto Nacional de Estudos e Pesquisas Educacionais Anísio Teixeira (Inep), o Sinaes é coordenado pela Comissão Nacional de Avaliação da Educação Superior (Conaes).
}

TrabalhoNecessário - www.uff.br/trabalhonecessario; Ano 13, No 21/2015. 


\section{Trabalhonecessário}

Issn: 1808 - 799X

ano 13, número $21-2015$

(Seres), Comissão Nacional de Avaliação da Educação Superior (Conaes) e Instituto Nacional de Estudos e Pesquisas Educacionais Anísio Teixeira (Inep). De sua parte, a(s) Agência (s) Nacional(is) de Acreditação integra(m) a Rede de Agências Nacionais de Acreditação do Mercosul (Rana).

Em outras palavras: as ANAs, órgãos executivos do Sistema Arcu-Sul, organizam-se numa Rede, denominada Rede de Agências Nacionais de Acreditação, que cria suas próprias regras de funcionamento e toma decisões por consenso em nível da política supranacional. Inserida na estrutura do SEM, a Rana ${ }^{25}$ responde diretamente à Comissão Regional Coordenadora de Educação Superior e à Reunião de Ministros de Educação, sendo responsável pelo Sistema de Acreditação de Cursos de Graduação no Mercosul e Estados Associados Arcu-Sul26.

Para Sobrinho (2008), existe uma tendência a substituir o reconhecimento pela acreditação, uma vez que esta última, valorizada internacionalmente, procede à avaliação tanto institucional quanto de cursos. A cultura da avaliação, que hoje faz parte da realidade educacional brasileira, foi uma das linhas programáticas do Compromisso de Brasília (op. cit., 1998a), coerentemente com o Protocolo de Intenções (Mercosul/SEM, 1991). Os ministros de educação alinhavaram as condições operativas para obter a comparabilidade e convergência dos sistemas nacionais por meio da criação de Agência Credenciadora Nacional, em todos os países membros, tornando possível, assim, a convergência das políticas educativas supranacional e nacional

\footnotetext{
${ }^{25}$ Vale conferir sua posição no organograma acima.

26 O Sistema de Acreditação Regional de Cursos de Graduação do Mercosul (Arc-Sul) veio substituir, no ano de 2008, o Mexa que, por sua vez, foi formulado, em 1998, no Memorando de Entendimento sobre a Implementação de um Mecanismo Experimental de Credenciamento de Cursos para o Reconhecimento de Títulos de Graduação Universitária nos países do Mercosul. Entretanto, somente mais tarde, foi implementado na vigência do Plano Estratégico 2001-2005. O Mexa vigorou entre os anos de 2003 e 2006, credenciando os então selecionados cursos de Agronomia, Engenharia e Medicina, bem como reconhecendo seus expedidos diplomas. Cf. http://arcusul.mec.gov.br/index.php/pt-br/descricao
} 


\section{Trabalhonecessário}

Issn: 1808 - 799X

ano 13, número $21-2015$

Os ministros que assinaram o Plano Trienal 1998-2000 comprometeramse, a "pressionar os sistemas educacionais para melhorar e controlar a qualidade da educação por eles oferecida a fim de assegurar a formação de competências (saberes, práticas e atitudes) equivalentes e facilmente credenciáveis, num espírito de integração regional" (Mercosul/SEM, 1998a). A citação da Presidente do Inep (1995-2002), Maria Helena Guimarães de Castro, é elucidativa:

O Brasil entrou neste esforço a partir de 1995, de implantação de sistemas nacionais de avaliação e de indicadores educacionais, criando um eficiente sistema de informações que abrange todos os níveis e modalidades de ensino, da educação infantil à pósgraduação, numa clara diretriz de governo sobre a importância estratégica de se criar mecanismos de avaliação para 0 monitoramento dos sistemas de ensino (...), cooperação internacional, com os objetivos de adquirir conhecimento, compartilhar experiências e expor o Brasil a comparações com outros países (Castro, s/d) ${ }^{27}$.

Desde então, a Coordenação de Aperfeiçoamento de Pessoal de Nível Superior (Capes) encarrega-se da avaliação da pós-graduação e recomendação de cursos, enquanto o Inep incumbe-se da graduação, sendo a regulação de atribuição da Secretaria de Educação Superior (SESu) e do Conselho Nacional de Educação (CNE).

A partir das Leis no 9131/1995 e no 9394/1996 (LDB), foram progressivamente implementados mecanismos de avaliação, com ênfase em resultados, produtividade, eficiência e controle do desempenho frente a um padrão estabelecido e prestação de contas: Exame Nacional de Cursos, realizado por concluintes de cursos de graduação; Questionário sobre condições socioeconômicas do aluno e suas opiniões sobre as condições de ensino do curso freqüentado; Análise das Condições de Ensino; Avaliação das Condições de Oferta; Avaliação Institucional dos Centros Universitários. Estes instrumentos

\footnotetext{
${ }^{27}$ Disponível em Disponível em http://dc.itamaraty.gov.br/publicacoes/textos-do-brasil-7
} 


\section{Trabalhonecessário}

Issn: 1808 - 799X

ano 13, número $21-2015$

de avaliação foram incorporados ao Sinaes, em vigor desde 2004, que possui instrumentos complementares (auto-avaliação, avaliação externa, Exame Nacional de Desempenho de Estudante).

Aqui cabe um parêntese. Tramita na câmara dos deputados, o Projeto de Lei 4372/12, do Executivo, que cria o Instituto Nacional de Supervisão e Avaliação da Educação Superior (Insaes), uma autarquia que, vinculada ao MEC, assumirá a tarefa do Inep nos processos de avaliação, acreditação e supervisão dos cursos de graduação das instituições federais, privadas e beneficentes de ensino superior, no Brasil. Alvo de contenda, o Insaes deverá aplicar penalidades e instrumentos previstos na legislação de modo a intervir nas IES. Entretanto e ao que tudo indica, a criação do Insaes não elidirá as atribuições da Conaes e do Inep junto à Rana ${ }^{28}$. Fecha-se o parêntese.

Em nível regional, o processo de criação do sistema de credenciamento e reconhecimento de títulos avança, materializando-se em programas como, o Marca e o Arcu-Sul, dos quais o Brasil vem liderando muitas das ações, nos últimos mandatos de governo (2003-2014), pelo papel de destaque que assume na política de building blocks, bem como da responsabilidade do Inep frente à secretaria da Rana.

Não há, ainda, estatísticas sobre os processos de avaliação e acreditação que possam ser comparáveis regionalmente. Segundo o Plano de Ação do Setor Educacional do Mercosul 2011-2105, tais processos não seguem o mesmo ritmo em todos os países do bloco. Estima-se que aproximadamente 500 cursos de graduação foram acreditados ${ }^{29}$.

${ }^{28}$ Cf. Brasil. Conaes (2013).

${ }^{29} \mathrm{No}$ Brasil, até o momento, 47 cursos participaram, do processo de acreditação: 14 de Engenharia: Civil (UFRGS, UPF, UEM, UPG); Alimentos (UFV); de Materiais (UPG, UFRGS); Produção Mecânica (CU do IMT); Elétrica (USP, UFRGS, UFMG, UNESP, UFCG); Mecânica (UFU, UFRJ); Química ( PUC-RJ Unicamp; 17 de Agronomia (UnB, UFU, UPF, UEM, UniMontes, UEPG, UniOeste, , UNESP, UFED, UEL); 8 de Arquitetura (UPF, UFRGS, UniRitter, UniFUMEC, PUC-Pr, UniSinos, UFMG, UFRGN); 5 de Enfermagem (UnB, UniOeste, FAMENA, PUC-SP, UniRio); 3 de Medicina: FCMSCSP, UEL, UFSP); 5 de Medicina Veterinária (UnB, UFPr, UFF, 


\section{Trabalhonecessário}

Issn: 1808 - 799X

ano 13, número $21-2015$

Coerentemente com o acordo celebrado entre a Comissão Regional de Educação Superior do Mercosul|30 e o GATS, em 2000, visando a liberalização progressiva dos serviços educacionais no ensino superior, esses processos de avaliação e credenciamento, apoiados financeiramente pelo $\mathrm{BID}^{31}$, consideram, no mínimo, os seguintes aspectos: contexto institucional, recursos humanos, infraestrutura e projeto acadêmico pautado na formação e avaliação por competências profissionais e ação investigativa.

Concebido como política de Estado, o Arcu-sul visa a formação de recursos humanos qualificados (Mercosul/CMC/Decisão no17/ 2008) como parte de uma comunidade científica coesa, ao mesmo tempo em que costura o Espaço Educacional Comum, tornando a educação superior regionalizada.

A coesão vem sendo construída por meio de uma estratégia de produção e organização do consenso, sutil, mas não menos importante. Ela é impulsionada por mediação dos Estados, que realizam o convite às instituições de educação superior a submeterem à acreditação os cursos previamente indicados pela Reunião de Ministros de Educação do Mercosul.

Para se candidatar ao Sistema ARCU-SUL a instituição interessada, por meio de seu coordenador de curso, com aprovação do Pró-Reitor de Graduação ou cargo equivalente, deve assinar um termo de Compromisso de Participação Voluntária no processo de Acreditação pelo Sistema ARCU-SUL (modelo em anexo) e o enviar por meio eletrônico à Coordenação do Sistema ARCU-SUL, para o endereço eletrônico:

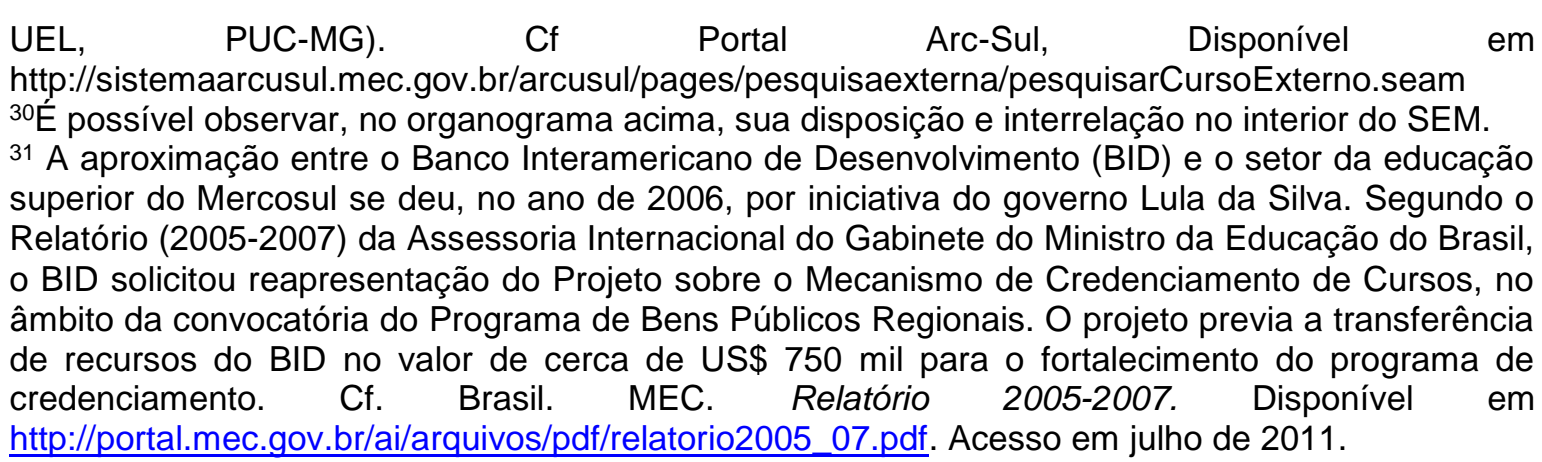

TrabalhoNecessário - www.uff.br/trabalhonecessario; Ano 13, No 21/2015. 


\section{Trabalhonecessário}

Issn: 1808 - 799X

ano 13, número $21-2015$

conaes.mercosul@mec.gov.br, no período de 01 a 30 de maio de 2009. Uma vez recebido o Compromisso de Participação Voluntária, a CONAES informará à Instituição candidata a data de realização da reunião técnica de orientação para auto-avaliação do curso nos padrões do Sistema ARCU-SUL. A reunião técnica de orientação deverá ocorrer em Brasília até no máximo 15 (quinze) dias após o prazo de recebimento do Compromisso de Participação Voluntária (Brasil/MEC/Conaes, 2009).

No Brasil, atualmente, estão envolvidos no processo de acreditação pelo Arcu-Sul os cursos de Agronomia, Arquitetura, Enfermagem, Engenharia (nas modalidades Alimentos, Civil, Elétrica, Materiais, Mecânica, Produção e Química), Medicina, Odontologia e Medicina Veterinária. Segundo Sérgio Franco, então presidente da Conaes, no ano de 2007, o Arcu-sul tem "como objetivo fomentar a qualificação da educação superior, certificando os cursos com um selo de padrão de qualidade como a certificação ISO 9000"32. Neste sentido, ainda que não obrigadas a submeterem os cursos ao processo de acreditação, as IES acabam por aderir ao processo. Garantem, assim, oficial e publicamente, a validez das titulações acadêmicas e habilitações profissionais, em escala regional, para o exercício da docência e atividades de pesquisa no âmbito de convênios ou tratados ou acordos bilaterais, multilaterais e regionais que venham a ser celebrados a esse respeito ${ }^{33}$.

Sempre associados ao Programa Marca (op, cit.), esses processos de avaliação e acreditação se articulam e ampliam no âmbito regional, tendo, a Capes e a SESu, no Brasil, papel decisivo na execução do Programa. Este programa de mobilidade beneficia estudantes, docentes-pesquisadores e gestores vinculados aos cursos acreditados pelo Arcu-Sul.

Para os discentes, o Programa oferta bolsas de estudos para intercâmbio, durante um semestre letivo, em instituição de outro Estado Parte ou Associado,

\footnotetext{
${ }^{32}$ Cf. Magalhães (2007).

33 Cabe lembrar a Decisão no 04/99 do SEM/Mercosul, anteriormente citada, oferece a possibilidade de exercício de atividades docentes em nível regional.
}

TrabalhoNecessário - www.uff.br/trabalhonecessario; Ano 13, No 21/2015. 


\section{Trabalhonecessário}

Issn: 1808 - 799X

ano 13, número $21-2015$

com aproveitamento e reconhecimento de estudos, tanto na universidade de origem quanto na instituição de destino, respectivamente. Quanto ao corpo docente, oferece fomento para execução de projetos de pesquisa interinstitucionais, propiciando a cooperação regional de docentes-pesquisadores; e propicia a consecução dos objetivos de integração e regionalização da educação envolvendo gestores e coordenadores de instituições de ensino superior (Mercosul/SEM/ProMarca, 2007).

\section{A Institucionalização da educação superior em âmbito birregional (UE- Mercosul): primeiras aproximações}

O processo de integração político-econômica regional, que acaba por integrar também a educação, não ocorre apenas como meio de o bloco oferecer resistência às sucessivas negociações multilaterais de ordem econômica stricto sensu. Ele abre espaço para uma relação de tipo cooperação antagônica ${ }^{34}$ entre blocos. Relação que engendra um conjunto de protocolos de comunicação, informação, transmissão de dados, de transferência de tecnologias entre indústrias, de inovação industrial, bem como de cooperação institucional (gestão administrativa e pedagógica) e de formação científica e tecnológica de pessoal qualificado.

Robertson (2009, p. 415) aponta para a institucionalização da educação superior nas relações interregionais, via UE com o Processo de Bolonha. De fato, o Universitários Mercosul - Programa de Mobilidade Mercosul em Educação Superior, projeto de cooperação entre UE e Mercosul bem evidencia o papel

\footnotetext{
${ }^{34}$ Marini (op. cit.).
}

TrabalhoNecessário - www.uff.br/trabalhonecessario; Ano 13, No 21/2015. 


\section{Trabalhonecessário}

Issn: 1808 - 799X

ano 13, número $21-2015$

central que a educação ocupa nos processos de integração regional e na relação entre blocos ${ }^{35}$.

Firmado no ano de 2008 e financiado em parte pela UE, este Programa tem como fito organizar um sistema integrado de mobilidade articulando diferentes programas, de modo a "impulsionar e fortalecer programas de mobilidade de estudantes, estagiários, docentes, pesquisadores, gestores, diretores e outros profissionais da educação" (Mercosul/SEM, 2011), coerentemente, é claro, com os Planos do Setor Educacional do Mercosul 2006 2010 e 2011-2015 (op, cit.).

Neste sentido estão sendo executados dois programas: Programa de Mobilidade do Mercosul (PMM) e Programa de Apoio ao Setor Educacional do Mercosul (Pasem). O primeiro visa a que estudantes universitários dos países intra-Mercosul sejam selecionados como beneficiários de bolsas de estudo similares ao do Marca. Mas, à diferença dos estudantes beneficiários do programa Marca, o PMM destina-se aos jovens matriculados em cursos que não passaram pelo processo de credenciamento do sistema Arcu-Sul.

A mobilidade ocorre através da participação em cursos, projetos de pesquisas e programas de extensão, garantindo o reconhecimento pleno das atividades desenvolvidas (ensino, pesquisa, extensão) na universidade de destino por parte das universidades de origem dos estudantes. No que diz respeito às atividades de ensino segue, ainda de forma tímida, o sistema de transferência de créditos a que me referi anteriormente.

Quanto ao Pasem, ele se desenvolve em torno do fortalecimento da formação docente (iniciação à docência, formação inicial em serviço, formação continuada em serviço, educação infantil, ensino de Ciências, ensino de Português e Espanhol, Uso das tecnologias da educação na formação docente, e

${ }^{35}$ Para maiores detalhes, ver os sites do SEM do referido Programa disponíveis em http://edu.mercosur.int/pt-BR/programas-e-projetos.html e http://universitariosmercosur.org/sitio/index.php?mod=html\&func=load\&lang=pt\&value=02\#sthash . 8sd4uLZz.dpuf, respectivamente.

TrabalhoNecessário - www.uff.br/trabalhonecessario; Ano 13, Nº 21/2015. 


\section{Trabalhonecessário}

Issn: 1808 - 799X

ano 13, número $21-2015$

gestão, implementação e avaliação de políticas de formação docente), cujas metas e objetivos foram estabelecidas no Plano Estratégico do SEM. O Programa, em sua segunda fase de execução, vem sendo desenvolvido na Argentina, Brasil, Paraguai e Uruguai, sob a coordenação do Ministério de Educação da Argentina.

Toda essa dinâmica do SEM revela-se como um tema de estudo complexo, na medida em que, apesar de seus quase 25 anos de existência, é um fenômeno novo, silencioso e pouco estudado no Brasil. Analisar as modificações que vêm ocorrendo na educação superior brasileira à luz dos propósitos e concretizações do SEM, pode trazer contribuições em estudos baseados nas disputas de forças políticas e estratégias de organização administrativo-pedagógicas e de funcionamento e institucionalização da educação superior em níveis nacional e regional.

\section{Considerações finais}

Concluímos a análise sobre as recentes modificações ocorridas na educação superior brasileira à luz dos propósitos e concretizações do SEM retornando ao início deste texto, quando se aponta que temas como educação para o desenvolvimento econômico; produção e transferência de ciência e tecnologia; cultura, diversidade cultural e integração regional, entre outros, vem assumindo o caráter de gestão supranacional, com implicações na formulação de políticas e na ação governamental em nível nacional.

Os problemas levantados colocam a questão da relação trabalho e educação como parte da necessidade de o capital subjugar, internacional e regionalmente, o trabalho e a educação. Com efeito, os processos de reforma e de contrarreforma não são executados de cima para baixo (Gramsci, 2002), 


\section{Trabalhonecessário}

Issn: 1808 - 799X

ano 13, número $21-2015$

porquanto, a relação trabalho e educação vincula-se às relações capitalistas de produção, de poder e de classe, que acabam por determinar as modalidades de ajuste a serem implantadas e implementadas no e pelo Estado. É pelas contradições internas e disputas entre classes e intraclasses que o capitalismo assume particularidades e especificidades diferentes em cada Estado-Nação.

Contudo, não se pode negar o caráter impositivo das recentes modificações na educação superior, sob os marcos do SEM.

Ainda que estudiosos na área das relações internacionais e alguns veículos de informação apontem para trajetória do Mercosul como um desenvolvimento vacilante; mesmo que seja um processo de integração de cujas questões de ordem econômica e geopolíticas são predominantemente marcadas por circunstâncias e determinações da política macroeconômica e de pressões de setores empresarias internos em nível nacional, o Mercosul representa uma das formas institucionais mais avançadas no domínio dos assuntos educacionais.

Concorda-se com Perrota (2014) quando afirma que a integração da educação, por mediação do SEM, avança de forma gradual e contínua. Desde a sua criação, o Mercosul Educacional vem estabelecendo um arcabouço normativo-institucional de modo a educação, particularmente a educação superior responder à dinâmica da internacionalização da economia/tecnologia.

A avaliação junto à mobilidade estudantil e de pessoal qualificado tornou-se vetor direcionador da reforma educativa em nível nacional, que vem sendo executada por meio de programas como o Marca, o Pasem, o PMM e o processo de credenciamento do sistema Arcu-Sul.

No século XIX, Marx e Engels (2004) já apontavam para a internacionalização do conhecimento como processo concreto, decorrente da natureza tendencial do capitalismo de se expandir globalmente em busca de novos mercados. A burguesia, afirmavam, engendra certo tipo de universalização da interdependência das nações na "produção intelectual". 


\section{Trabalhonecessário}

Issn: 1808 - 799X

ano 13, número $21-2015$

A resposta da classe trabalhadora a este movimento burguês, do que, mais tarde, Gramsci observou como uma tentativa de construir uma internacional capitalista, só poderia ser a união dos trabalhadores de todos os países em torno da educação pública, gratuita de formação omnilateral.

Sendo a relação trabalho e educação mediação para o desenvolvimento sócio-econômico, político e cultural do ser social na direção da emancipação humana, ela não deve padecer interessada imediatamente aos interesses econômicos mercadológicos. Não se trata, portanto, de ser contra os processos de regionalização e integração da educação, mas ter clareza do porque deste movimento de modo a direcioná-los para os interesses universais da classe trabalhadora.

\section{Referências}

ANTUNES, Fátima. Governação global e diretrizes internacionais para a educação na União Européia: entrevista. Revista Perspectiva. Santa Catarina: Centro de Ciências da Educação/UFSC, v. 23, no 2, 2005, p. 449-465.

BRASIL. Ministério da Educação. Comissão Nacional de Avaliação da Educação Superior. Convite aos cursos de agronomia e arquitetura de instituições de ensino superior brasileiras para participarem do processo de acreditação pelo Sistema ARCU-SUL. Brasília: CONAES, 2009.

BRASIL. Ministério da Educação. Comissão Nacional de Avaliação da Educação Superior. Ponderações da CONAES referentes à implatação do PL 4.372/2012 (após aprovação pelo Congresso Brasileiro), aprovadas pela CONAES na 101 reunião ordinária de 15 de outubro de 2013. Brasília: CONAES, 2013.

CASTRO, Maria Helena Guimarães de. A participação do Brasil em estudos e avaliações educacionais comparados internacionais. In: Textos do Brasil $n^{\circ} 7$ Educação para um desenvolvimento humano e social no Brasil. Brasil, Ministério das Relações exteriores: Departamento Cultural, s/d. Disponível em http://dc.itamaraty.gov.br/imagens-e-textos/revista-textos-dobrasil/portugues/edicao-numero-7

COMISSÃO ECONÔMICA PARA AMÉRICA LATINA E CARIBE. O investimento estrangeiro direto na América Latina e Caribe. Nações Unidas: CEPAL, 2010. 


\section{Trabalhonecessário}

Issn: 1808 - 799X

ano 13 , número $21-2015$

DREIFUSS, René. Época das perplexidades: mundialização, globalização e planetarização; novos desafios. 2. ed. Petrópolis: RJ: Vozes, 1997.

DREIFUSS, René. Transformações: matrizes do século XXI. Petrópolis: RJ: Vozes, 2004.

FULQUET, Gaston. A. El Proyecto Educativo para el MERCOSUR y los Debates en torno a la Internacionalización de la Educación Superior. Buenos Aires, Ar.: CAEI, 2006.

GRAMSCI, Antonio. Cadernos do cárcere. v.3. Maquiavel; Notas sobre o Estado e a política. 3.ed. Rio de Janeiro: Civilização Brasileira, 2007.

GRAMSCI, Antonio. Cadernos do Cárcere, v.5. I/ Risorgimento - notas sobre a história da Itália. 2.ed. Rio de Janeiro: Civilização Brasileira, 2002.

GRAMSCI, Antonio. Escritos políticos [1910- 1919]. Lisboa, Pt.: Seara Nova, 1976.

GRAMSCI, Antonio. Escritos políticos [1917-1933].Cerro del Agua, Mx: Siglo XXI Editores, 1981.

HUNTINGTON, Samuel. A terceira onda: a democratização no final do século $X X$. Rio Janeiro: Ática, 1994.

MAGALHÃES, Gláucia. Selos de qualidade para cursos do Mercosul. Ministério da Educação/Notícias. Brasília: MEC/Notícias, [2007]. Disponível em: http://portal.mec.gov.br/index.php?option=com content\&task=view\&id=8009.

MARX Karl; ENGELS, Freidrich. Manifesto do Partido Comunista. São Paulo: Martin Claret, 2004.

MARINI, Ruy Mauro. Dialética da dependência. Petrópolis, RJ: Vozes: Buenos Aires, Ar.: CLASO, 2000.

MARINI, Ruy Mauro. La acumulación capitalista mundial y el subimperialismo. In: Cuadernos Políticos. México: Ediciones Era, no 12, abr./jun., 1977.

MERCOSUL. CMC. Decisão no 04/94. Protocolo sobre Integração Educativa e Reconhecimento de Certificados, Títulos e Estudos de Nível Primário e Médio Não Técnico. Montevideo, Uy.:Mercosul: CMC, 1994.

MERCOSUL. Conselho do Mercado Comum. Decisão no-15/08. Disposições Transitórias: Atualiza/Modifica e Implementa a Tabela de Equivalências Anexa ao Protocolo de Integração Educativa e Reconhecimento de Certificados, Títulos e Estudos de Nível Fundamental e Médio Não Técnico. Montevideo, Uy.:Mercosul: CMC, 2008.

MERCOSUL. Conselho do Mercado Comum. Decisão no 07/95. Protocolo de Integração Educativa e Revalidação de Diplomas,Certificados, Títulos e Reconhecimento e Estudos de Nível Médio Técnico. Montevideo, Uy.:Mercosul: CMC, 1995.

MERCOSUL. Conselho do Mercado Comum. Decisão CMC no 11/96. Protocolo de Integração Cultural do Mercosul. Montevideo, Uy.:Mercosul: CMC, 1996. 


\section{Trabalhonecessário}

Issn: 1808 - 799X

ano 13 , número $21-2015$

MERCOSUL. Conselho do Mercado Comum. Decisão no 17/2008. Acordo sobre a criação e a implementação de um sistema de credenciamento de cursos de graduação para o reconhecimento regional da qualidade acadêmica dos respectivos diplomas no Mercosul e Estados Associados. Montevideo, Uy.:Mercosul: CMC, 2008.

MERCOSUL. Conselho do Mercado Comum. Programa-Quadro de Ciência, Tecnologia e Inovação do Mercosul, período 2008-2012, de 30/06/2008. Montevideo, Uy.:Mercosul:CMC, 2008.

MERCOSUL. Conselho do Mercado Comum. Protocolo de integração educacional para a formação de recursos humanos no nível de pós-graduação entre os Estados Partes do Mercosul. Montevideo, Uy.: Mercosul: CMC, 1996.

MERCOSUL. Conselho do Mercado Comum. Sobre o Mercosul. Montevideo, Uy.:Mercosul:CMC, s/d.

MERCOSUL. Setor Educacional do Mercosul. Compromisso de Brasília. Montevideo, Uy::Mercosul:SEM, 1998a.

MERCOSUL. Setor Educacional do Mercosul. Decisão no13/1998. Plano Trienal e Metas do Setor Educacional. Montevideo, Uy.:Mercosul:SEM, 1998.

MERCOSUL. Setor Educacional do Mercosul. Decisão no 03/1997. Protocolo de Admissão de Títulos y Graus Universitários para o Exercício de Atividades Acadêmicas dos Países do Mercosul. Montevideo, Uy::Mercosul:SEM, 1997.

MERCOSUL. Setor Educacional do Mercosul. Decisão no 04/1999. Protocolo de Admissão de Títulos y Graus Universitários para o Exercício de Atividades Acadêmicas dos Países do MERCOSUL. Montevideo, Uy.:Mercosul:SEM, 1999. MERCOSUL. Setor Educacional do Mercosul. El Acuerdo General de Comercio de Servicios y la Educación. Vinculación con el Mercosur. In: Ata da VI Reunião da Comissão Regional Coordenadora de Educação Superior. Montevideo, Uy.:Mercosul:SEM:CRES, 2002.

MERCOSUL. Setor Educacional do Mercosul. Instâncias do Setor Educacional do Mercosul. Uy.:Mercosul, 2012. http://edu.mercosur.int/pt-BR/mercosuleducacional/instancias.html

MERCOSUL. Setor Educacional do Mercosul. Memorando de Entendimento sobre a implementação de um mecanismo experimental de credenciamento de cursos para o reconhecimento de títulos de graduação universitária nos países do MERCOSUL (MEXA), de 19/06/1998. Montevideo, Uy.:Mercosul:SEM, 1998b.

MERCOSUL. Setor Educacional do Mercosul. Plano de Ação 2006-2010. Montevideo, Uy.:Mercosul:SEM, 2006.

MERCOSUL. Setor Educacional do Mercosul. Plano Estratégico 2001-2005. Montevideo, Uy.:Mercosul:SEM, 2001.

MERCOSUL. Setor Educacional do Mercosul. Plano de Ação 2011-2015. Montevideo, Uy.:Mercosul:SEM, 2011.

MERCOSUL. Setor Educacional do Mercosul. PMM - Programa de Mobilidade MERCOSUL/Fase Piloto. Montevideo, Uy.:Mercosul:SEM, 2012. 


\section{Trabalhonecessário}

Issn: 1808 - 799X

ano 13 , número $21-2015$

MERCOSUL. Setor Educacional do Mercosul. ProMARCA. Montevideo, Uy.:Mercosul:SEM, 2007.

MERCOSUL. Setor Educacional do Mercosul. Protocolo de Intenções, de 13/12/1991. Montevideo, Uy.: Mercosul:SEM, 1991.

MERCOSUL-UNIÃO EUROPÉIA. Acordo Quadro Interregional de Cooperação entre a Comunidade Européia e o Mercado Comum Sul, de 15/12/1995. Montevideo, Uy.: Mercosul:UE, 1995.

MERCOSUL-UNIÃO EUROPÉIA. Comunicado Conjunto da Reunião Ministerial MERCOSUL-TROIKA UE, de 14/07/2009.Montevideo, Uy.:Mercosul:UE, 2009.

MERCOSUL-UNIÃO EUROPÉIA. Declaração Comum MERCOSUL-União Européia, de 17/12/2007. Montevideo, Uy.:Mercosul:UE, 2007.

MERCOSUL-UNIÃO EUROPÉIA, Declaração Comum MERCOSUL-TROIKA EU, de 17/05/2008. Montevideo, Uy.:Mercosul:UE, 2008.

MERCOSUL-UNIÃO EUROPEIA, Documento de Estratégia Regional 2007-2013. Montevideo, Uy.:Mercosul:UE, 2007.

MÉSZÁROS, István. O século XXI: socialismo ou barbárie?. São Paulo: Boitempo, 2003.

MÉSZÁROS, István. Para além do capital. 2 reimp. 1. ed. São Paulo: Boitempo, 2006.

NOVOA, Luis Fernando. O Brasil e seu "desbordamento": o papel central do BNDES na expansão das empresas transnacionais brasileiras na América do Sul. In: Intituto Rosa Luxemburg Stitung et al (Org.). Empresas transnacionais brasileira na América Latina: um debate necessário. São Paulo: Expressão popular, 2009, p. 188-204.

OLIVEIRA, Francisco. Crítica à razão dualista - $O$ ornitorrinco. São Paulo: Boitempo, 2003.

OLIVEIRA, Francisco. O direitos do anti-valor: a economia política da hegemonia imperfeita. Petrópolis, RJ: Vozes, 1988.

PERROTA, Daniela. El regionalismo de la educación superior en el MERCOSUR como vector de internacionalización: un acercamiento desde la política regional de acreditación. In: Revista Latinoamericana de educación comparada. SAERCE: Ar, ano 5, n. 5, 2014, p. 68-92.

ROBERTSON, Susan. O processo de Bolonha da Europa torna-se global: modelo, mercado, mobilidade, força intelectual ou estratégia para construção do Estado?. Revista Brasileira de Educação, v.14. no 42, set./dez.2009.

SOBRINHO, José Dias. Acreditação da educação superior. Anais do $2^{\circ}$ Seminário Internacional de Avaliação da Educação Superior - 2008. Brasília: MEC/CONAES, 2008.

TREIN, Franklin; CAVALCANTI, Flávia Guerra. Uma análise crítica do acordo de associação estratégica entre a União Européia e a América Latina e o Caribe - A Cúpula de Viena. Revista Brasileira de Política Internacional. Brasília: IBRI, v.50, no 1,2007, p.66-85. 


\title{
Trabalhonecessário
}

\author{
Issn: 1808 - 799X \\ ano 13, número $21-2015$
}

UNIÃO EUROPEIA. Declaração de Viena: Quarta cimeira UE-ALC, Áustria: Viena, 2006.

UNIÃO EUROPEIA. Declaração de Madrid: sexta Cimeira UE-ALC, Espanha: Madrid, 2010.

Recebido em 04 de maio de 2015. Aprovado em 08 de setembro de 2015. 